\title{
Alzheimer's Dementia: Peri-menopausal Estrogen Is a Preventative Strategy for Women
}

\author{
Joseph Loze Onwude \\ The Croft, Warley Road, Great Warley, Brentwood CM13 3HT, UK.
}

\author{
How to cite this paper: Joseph Loze \\ Onwude. (2021) Alzheimer's Dementia: \\ Peri-menopausal Estrogen Is a \\ Preventative Strategy for Women. \\ International Journal of Clinical and \\ Experimental Medicine Research, 5(1), \\ 25-32. \\ DOI: 10.26855/ijcemr.2021.01.006 \\ Received: December 2, 2020 \\ Accepted: December 30, 2020 \\ Published: January 14, 2021 \\ *Corresponding author: Joseph Loze \\ Onwude, The Croft, Warley Road, \\ Great Warley, Brentwood CM13 3HT, \\ UK. \\ Email: jlonwude1@gmail.com
}

\begin{abstract}
Alzheimer's dementia (AD) predominantly affects women, and it has no cure when it becomes established. As the current biggest killer of women in the United Kingdom, it became incumbent to explore all preventive strategies. Based on the knowledge that Alzheimer's dementia is homed in the hippocampus and that this area is suffused with estrogen receptors, we explored whether there was a link that might suggest therapeutic or preventive strategies. We found that there was evidence that the hippocampus, the primary area of the brain that we used for declarative memory became deplete with estrogen receptors in the menopause. We also found other pointers which included that hippocampal pathology is central to the development of $\mathrm{AD}$ and that the hippocampal shape and volume can predict the onset of AD. There were further of in-vitro and in-vivo support that peri-menopausal estrogens could reduce the incidence of $\mathrm{AD}$ in women by up to $35 \%$.
\end{abstract}

\section{Keywords}

Alzheimer’s Dementia, Peri-menopausal Estrogens, Prevention

\section{The dementia pandemic: the socio-economic impact}

Dementia is now the biggest killer of women in the UK, surpassing heart disease, which remains the leading cause of death for men [1]. This progressively worsening global pandemic is currently estimated to affect 50 million people worldwide, with projections of increasing to 132 million by 2050. The majority of sufferers live in low and middle-income countries. The global costs of caring for dementia sufferers are estimated at US\$800 billion current, projected to rise to US\$2 trillion by 2030. The human costs include profound disability and dependence for the afflicted, and risk of developing depression and anxiety disorders for the carers [2]. Thus, the dementia pandemic poses a truly global challenge to which the world may only have recently woken up.

The four common types of dementia are Alzheimer's Disease (AD), vascular dementia, Lewy body dementia and fronto-temporal dementia, with $\mathrm{AD}$ accounting for $70 \%$ of all cases, with a 1.8:1 female to male preponderance, and whose onset coincides with the decline in estrogen levels seen in the peri-menopause.

A recent Lancet Commission research identified nine potentially modifiable risk factors (low educational level in childhood, hearing loss, hypertension, obesity, smoking, depression, physical inactivity, social isolation, and diabetes) at different stages of life that, if eliminated, might prevent more than a third of cases of dementia [3]. It is difficult to see how, apart from physical exercise which increases hippocampal volume [4], these potentially modifiable risk factors could reduce the incidence of some forms of dementia such as AD.

This article provides evidence from in-vitro studies, animal experimentation and a growing body of human clini- 
cal research of how estrogen, a cheap, simple and safe hormone, when administered in the peri-menopausal transition, could prevent up to $35 \%$ cases of AD.

\section{The pathophysiology of $\mathrm{AD}$ - a central role for the hippocampus:}

The hippocampus is the area of the brain that we use for learning and where memory is first formed. It is essential for declarative memory, that is, the conscious, intentional recollection of factual information, previous experiences and concepts [5]. The hippocampus is so central to brain function that scientists have long considered it a strong predictor for overall brain health [6]. Hippocampal pathology is central to the development of AD [7] and the hippocampal shape and volume can predict the onset of AD [8]. Hackert and colleagues [9] and O’Driscoll et al. [10] independently showed that the size of the hippocampus is associated with verbal memory performance. AD is associated with loss of declarative memory. The definitive cause of AD is the deposition and accumulation of abnormal protein fragments called Tau proteins and $\beta$-amyloid proteins, colloquially referred to as 'plaques and tangles' in the brain, which kill brain cells—a process that is known to start in the hippocampus. These abnormal proteins are pathognomonic of $\mathrm{AD}[11]$.

\section{The link between the menopause and hippocampal function}

The hippocampal area contains a large collection of estrogen receptors [12]. Generally, any area of the body that has a large collection of these receptors depends for its function on estrogen supply. The hippocampus shrinks in themenopause [13], and it is teleologically sound to link this to the well documented decline in verbal memory and the decline in estrogen levels [14]. Thus, the menopause has a negative effect on hippocampal function.

\section{Estrogen and Alzheimer's Dementia: in-vitro evidence that estrogen disrupts the pathological mechanisms that underpin the disease}

The pathognomonic elements of AD were described above [11]. In-vitro studies have shown that estrogens inhibit both Tau hyperphosphorylation and $\beta$-amyloid protein accumulation [15] as well as providing protection against $\beta$-amyloid proteinneuro-toxicity [16].

\section{Estrogens and Alzheimer's Dementia: evidence from in-vivo animal studies}

In vivo animal studies involving rodents have firmly established the beneficial effects of estrogens for brain anatomy, physiology and function. In normally aging female rats, along with decreased hormone levels, the number of estrogen receptors are reduced, with a specific reduction in estrogen receptor positive neurons in the Cornuammonis (the CA1 subfield) of the hippocampus [5]. Gould et al. [17] demonstrated that gonadal steroids are necessary for the maintenance of normal adult CA1 hippocampal pyramidal cell structure. Estrogen administration to ovariectomized rats also enhanced performance in hippocampus-dependent tasks such as spatial navigation and working memory [17]. More recent studies in ovariectomized rats have shown that estrogen replacement improves cell proliferation and cell survival and also promotes angiogenesis in the hippocampus [19].

\section{Estrogen Replacement Therapy (ERT) prevents Alzheimer's Disease in women: The Critical Perimenopausal Window}

The Critical Perimenopausal Window theory has been recognised for some time. With regards to AD, the evidence shows that if ERT is administered in the perimenopausal period, there is a potential to prevent Alzheimer's Dementia. This is consistent with the accepted wisdom that although the symptoms of dementia generally occur in later life, the disorder begins in midlife, around the ages 40-65 years [20]. Some studies have explored the critical window theory for the potential benefits of supplying ERT before the menopause. In a longitudinal cohort study, Shao et al. [21] showed that peri-menopausal ERT within 5 years of the menopause, plus use for 10 or more years was significantly associated with a 35\% reduced risk of AD (95\% CI 0.43-0.98). This finding is supported by other prospective cohort studies [22, 23]. ERT started after 5 or more years after the menopause was still associated with a 14\% reduced but not significant risk of Alzheimer’s Dementia (95\% CI 0.49-1.51) [21].

\section{Caution - combined estrogen + progestogen therapy (HRT) may increase the risk of AD}

The position of estrogen as the effective prevention is shown by the result that peri-menopausal combined HRT (Estrogen and Medroxyprogesterone acetate) within 5 years of the menopause and use for 10 or more years was associated with a non-significant 35\% reduced risk of Alzheimer's dementia (95\% CI 0.36-1.18) while pe- 
ri-menopausal ERT within 5 years of the menopause and use for 10 or more years was associated with a statistically significant 35\% reduced risk of Alzheimer’s Dementia (95\% CI 0.43-0.98) [21].

Shao et al. [21] also showed that oral combined estrogen + progestogens that menopausal HRT therapy 5 or more years after the onset of the menopause was associated with a 32\% increased but not significant risk of Alzheimer's dementia (95\% CI 0.78-2.24). This was confirmed by the Women's Health Initiative Memory Study [24], a randomized placebo controlled study of oral combined estrogen and progestogens where menopausal HRT 4 or more years after the menopause was associated with a significantly (doubled) increased risk of AD (Hazards Ratio 2.02, 95\% CI 1.21-3.48).

It is accepted that ERT does not reverse established AD [25, 26, 27]. Once a woman has developed AD, hormone replacement treatment, particularly combined estrogen + progestogen (HRT)does not help but might even worsen the condition.

\section{Estrogen prevents AD—a summary of the science}

The scientific basis for the development of $\mathrm{AD}$, which includes the influences of Tau proteins and $\beta$-amyloid proteins on brain cells and cell death and the knowledge that estrogens inhibit both Tau hyperphosphorylation and $\beta$-amyloid protein accumulation, as well as providing protection against $\beta$-amyloid protein neuro-toxicity is supported by in vivo experiments in rats.

Evidence from MRI shape analysis shows significant regional sparing of the medial aspect of the right hippocampal head and lateral aspect of the body extending to the tail, in the area corresponding to the Cornuammonis, including part of the subiculum, in hormone therapy users compared to non-users [28].

The results of the longitudinal prospective cohort studies are consistent [21, 22, 23]. This evidence from observational studies go some way to satisfy the most important conditions where an observational study can support a cause and effect relationship [29].

Firstly, there is a significantly reduced risk of Alzheimer's Disease when women used peri-menopausal estrogen replacement when measured by prospective studies [21, 22, 23]. Secondly, the results are consistent for different types of observational studies. One review identified three observational studies that support the theory of the critical window that ERT is associated with reduced risk of $\mathrm{AD}[21,22,23]$. Thirdly, experimental MRI studies of hippocampal volumes with or without estrogen are also supportive $[8,9,13,28,32]$. Fourthly, the results are consistent across countries [13, 28, 29].

Finally, there is abundant biologic plausibility. It is well established that Alzheimer's Disease starts in the hippocampus, the area for learning and memory, that the hippocampus is lush in estrogen receptors and suffers decreased volume and size in the menopause, and that peri-menopausal estrogens maintain the lushness of the hippocampi.

\section{The misguided fear of estrogen}

If perimenopausal ERT prevents Alzheimer's dementia, the elephant in the room could be fear of breast cancer from estrogen. It is well documented that there was a dramatic reduction in HRT prescriptions following the publication of the WHI studies in 2002 [33].

However, ERT given to women with prior hysterectomy, as opposed to combined HRT (estrogen and progestogen) in the peri-menopause or menopause does not increase the risk of breast cancer. At 7.1 years follow-up in the WHI ERT group compared to placebo, there was a 21\% reduced relative risk of breast cancer although this did not reach statistical significance (RR 0.79, 95\% CI 0.61 to 1.01). However, the overall cumulative breast cancer incidence over 10.7 years, with a mean follow-up of 11.8 years showed a significantly lower risk of breast cancer in the ERT group (RR $0.78,95 \%$ CI 0.63 to 0.96 ).

The absolute risk of breast cancer also significantly decreased over 10.7 years, mean follow-up from 37 per 1,000 women in the control group to 29 per 1,000 (95\% CI 23 to 35) in the ERT group. The overall cumulative risk remained lower after a median of 13 years follow-up (RR 0.80, 95\% CI 0.65 to 0.97). Thus, the evidence base has moved significantly from the fear that ERT may cause breast cancer to the evidenced position that it does not [34, 35].

\section{What about Men?}

Although there is a female preponderance to $\mathrm{AD}$ (1.8:1) and given the extent of the pandemic, there are large numbers of affected men too. It is interesting that hormonal factors, which seem to play a major part in the prevention of Alzheimer's Dementia in women have not been rigorously studied in men. However, the building blocks are 
known. Firstly, the hippocampus is replete with androgen receptors in rats [36]. Secondly, testosterone in men, like estrogen in women, attenuates $\beta$-amyloidtoxicity, the process that kills neurons in Alzheimer's disease [37]. Thirdly, low testosterone is associated with Alzheimer's Dementia in men (RR 1.48, 95\% CI 1.12-1.96, P = 0.006) [38]. There are obvious potential avenues for further research.

\section{Concluding remarks}

The key messages box shows that peri-menopausal estrogen can reduce by prevention the pandemic of Alzheimer's Dementia in women.

Based on an understanding of the patho-physiology of Alzheimer's Dementia, we have outlined cogent evidence (Evidence Box-Table 1) from in-vitro studies, animal experimentation and an established body of human clinical studies that estrogen could prevent up to $35 \%$ of cases of the disease, a significant proportion given the extent of the pandemic. In the absence of any preventive intervention for $\mathrm{AD}$, women should be offered a simple, safe and cheap medicine which is estrogen. This hormone is not only the most effective treatment for menopausal symptoms, but is also an effective intervention in the prevention of osteoporosis - another costly cause of morbidity and mortality in women.

The UK government has recently declared that "prevention must be the heart of the NHS long-term plan”, listing smoking, CVD and obesity as its main targets [39]. The dementia pandemic is not acknowledged as a target, perhaps in part because the existing focus is on current sufferers and resources are directed at further research. The progressively worsening nature of the dementia pandemic emphasizes that ultimately non sufferers will progress to be sufferers as they grow older. In such a scenario the urgency of acknowledging and adopting an already existing preventative strategy for $\mathrm{AD}$ - perimenopausal estrogen therapy-cannot be exaggerated. We therefore advocate that the maxim "care now, if cure later" should be replaced by "prevent now, care now, if cure later".

\section{Key Messages Box}

\begin{tabular}{|c|l|}
\hline 1 & $\begin{array}{l}\text { The pandemic of Alzheimer's Disease in women can be prevented to a significant degree by peri-menopausal Estrogen } \\
\text { Replacement Therapy (ERT) }\end{array}$ \\
\hline 2 & $\begin{array}{l}\text { Established Alzheimer's dementia is not reversed by either Estrogen Replacement Therapy (ERT) or combined HRT, and } \\
\text { could be made worse by the latter. }\end{array}$ \\
\hline 3 & $\begin{array}{l}\text { Estrogen Replacement Therapy (ERT) does not increase the risk of breast cancer. The reduced risk of breast cancer be- } \\
\text { comes more pronounced the longer ERT is used. }\end{array}$ \\
\hline 4 & $\begin{array}{l}\text { The known risk of breast cancer from oral progestogens in combined HRT in women with a womb is low. This can be re- } \\
\text { duced further by using intrauterine progestogen devices. }\end{array}$ \\
\hline 5 & $\begin{array}{l}\text { Estrogen Replacement Therapy (ERT) is a cheap and effective prevention strategy for preventing Alzheimer's Dementia } \\
\text { globally. }\end{array}$ \\
\hline
\end{tabular}

Evidence Box - Table 1

\begin{tabular}{|l|l|}
\hline 1 & $\begin{array}{l}\text { Evidence } \\
\text { In-vivo Animal Studies } \\
\text { Gould et al., 1990 } \\
\text { Removal of circulating gonadal steroids by ovariectomy of adult female rats resulted in a profound decrease in dendritic } \\
\text { spine density in CA1 pyramidal cells of the hippocampus. Estradiol replacement prevented the observed decrease in den- } \\
\text { dritic spine density; progesterone augmented the effect of estradiol within a short time period. Ovariectomy or gonadal } \\
\text { steroid replacement did not affect spine density of CA3 pyramidal cells or granule cells of the dentate gyrus. These results } \\
\text { demonstrate that gonadal steroids are necessary for the maintenance of normal adult CA1 hippocampal pyramidal cell } \\
\text { structure. } \\
\text { Packard \&Teather, } 1997 \\
\text { There is a time-dependent effect of Estradiol on memory storage processes. } \\
\text { Mehra et al., 2005 } \\
\text { Apart from the decreased hormone levels in the menopause, there are also a reduced number of Estrogen } \alpha \text { \& } \beta \text { receptors in } \\
\text { the normally aging female rat, with a specific reduction in Estrogen receptor positive neurons in the Cornuammonis (the } \\
\text { CA1 subfield) of the hippocampus. } \\
\text { Barouk et al., 2011 } \\
\text { Rodent studies in ovariectomized female rats show that Estrogen replacement promotes angiogenesis and improves cell } \\
\text { proliferation and cell survival in the hippocampus. }\end{array}$ \\
\hline
\end{tabular}




\begin{tabular}{|c|c|}
\hline 2 & $\begin{array}{l}\text { Patho-physiology of Alzheimer's Disease } \\
\text { Pike et al., } 2009 \\
\text { Alzheimer's Disease results from deposition and accumulation of abnormal protein fragments called Tau proteins and } \\
\beta \text {-amyloid proteins, which are pathognomonic for the disease. }\end{array}$ \\
\hline 3 & $\begin{array}{l}\text { In Vitro Therapeutic interventions with Estrogens } \\
\text { Braak \& Braak, 1990; Pike et al., } 2009 \\
\text { Estrogens inhibit } \beta \text {-amyloid protein accumulation. } \\
\text { Estrogens inhibit Tau hyperphosphorylation } \\
\text { Goodman et al., } \mathbf{1 9 9 6} \\
\text { Estrogen protects against } \beta \text {-amyloid protein neurotoxicity. }\end{array}$ \\
\hline 4 & 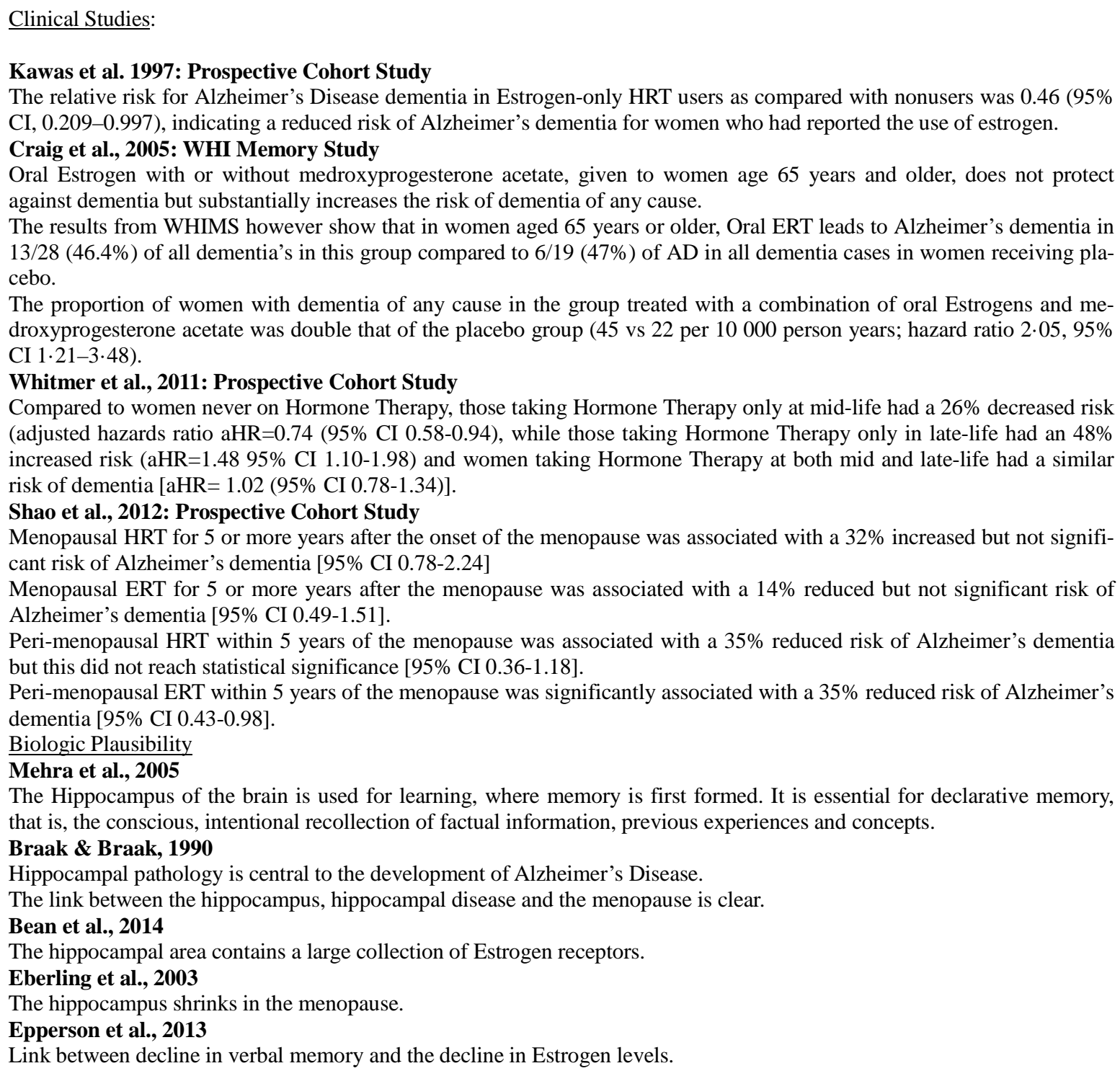 \\
\hline
\end{tabular}




\section{MRI Studies}

\section{Lord et al.2008}

Women using Estrogen therapy had larger left and right hippocampal volumes compared to men, and larger right hippocampal volumes compared to past users and never users.

There was a significant negative relationship between duration Estrogen therapy and hippocampal volume.

\section{Pintza and Haberg, 2015}

The main effect of hormone group showed a statistically significant difference in hippocampal volumes $(p=0.028)$. Both the right (3.2\%) and left (2.8\%) hippocampal volumes were larger in the Hormone therapy group but only significant for the right hippocampus $(\mathrm{p}=0.023)$.

5 This study provides support for the critical window theory demonstrating that Hormone therapy initiated in the perimenopause has neuroprotective properties.

\section{Csernansky et al., 2005}

Hippocampal shape and volume can predict the onset of Alzheimer's Disease.

\section{Hackert et al., 2002}

The size of the hippocampus is associated with verbal memory performance.

Eberling et al., 2003

Women taking ERT had larger right hippocampal volumes than women not taking ERT and larger anterior hippocampal volumes than men subjects and women subjects not taking ERT.

These findings suggest a neuroprotective effect of estrogen.

\section{ERT and Breast Cancer}

\section{Anderson et al., 2012: Randomised Controlled Trial\& Extended Follow-up}

When women on ERT were compared with women taking placebo, the $21 \%$ reduced risk in breast cancer was not statistically significant (RR 0.79, 95\%CI 0.61 to 1.01). Follow-up continued for a median of 5.8 years after the intervention phase.

The overall cumulative breast cancer incidence over the 10.7 years' mean follow-up (median 11.8 years) showed a significantly lower rate in the HT group (RR 0.78, 95\% CI 0.63 to 0.96 ).

The overall cumulative rate remained lower after a median of 13 years' follow-up (RR 0.80, 95\% CI 0.65 to 0.97 )

Zhang et al., 2007: Prospective Re-analysis Study of WHI 1992-2004

When consistent current users of ERT were compared with never users, the multivariable hazard ratios were 1.11 (95\% CI: 0.79-1.56) for total breast cancer and 1.13 (95\% CI: 0.77-1.64) for invasive cases.

These data, like those from the Women's Health Initiative, show no significant increase in breast cancer risk with use of oral conjugated estrogen alone $(0.625 \mathrm{mg} /$ day $)$, but a small increase or decrease in risk cannot be excluded.

\section{References}

[1] Office of National Statistics. (2016). https://www.ons.gov.uk/peoplepopulationandcommunity/birthsdeathsandmarriages/deat hs/bulletins/deathsregisteredinenglandandwalesseriesdr/20152.

[2] Mahoney, R., Regan, C., Katona, C., and Livingston, G. (2005). Anxiety and depression in family caregivers of people with Alzheimer disease: the LASER-AD study. Am J Geriatr Psychiatry, 13:795-801.

[3] Livingston, G., Sommerlad, A., Orgeta, V., Costafreda, G. C., Huntley, J., Ames, D., et al. (2017). Dementia prevention, intervention, and care. www.thelancet.com. Published online July 20, 2017.

[4] Erickson, K. I., Prakash, R. S., Voss, M. W., Chaddock, L., Hu, L., Morris, K. S., et al. (2009). Aerobic Fitness is Associated with Hippocampal Volume in Elderly Humans. Hippocampus, 19(10): 1030-1039.

[5] Mehra, R. D., Sharma, K., Nyakas, C., Vij, U. (2005). Estrogen receptor $\alpha$ and $\beta$ immunoreactive neurons in normal adult and aged female rat hippocampus: a qualitative and quantitative study. Brain Res., 1056: 22-35.

[6] Wnuk, A., Korol, D. L., Erickson, K. I. (2012). Estrogens, hormone therapy, and hippocampal volume in postmenopausal women. Maturitas, 73: 186-190.

[7] Braak, H., Braak, E. (1990). Neuropathological staging of Alzheimer-related changes. Acta Neuropathol., 182: $239-259$.

[8] Csernansky, J. G., Wang, L., Swank, J. J. G., Miller, J. P., Gado, M., McKeel, D., et al. (2005). Preclinical detection of Alzheimer's disease: hippocampal shape and volume predict dementia onset in the elderly. Neuroimage, 25: 783-792.

[9] Hackert, V. H., den Heijer, T., Oudkerk, M., Koudstaal, M., Hofman, A., Breteler, M. M. B. (2002). Hippocampal head size associated with verbal memory performance in nondemented elderly. Neuroimage, 17: 1365-1372.

[10] O’Driscoll, G. A., Florencio, P. S., Gagnon, D., Wolff, D., Anne-Lise, V., Benkelfat, C. M., et al. (2001). Amygdala-hippocampal volume and verbal memory in first-degree relatives of schizophrenic patients. Psychiatry Res., 107: 75-85.

[11] Pike, C. J., Carroll, J. C., Rosario, E. R., Barron, A. (2009). Protective actions of sex steroid hormones in Alzheimer’s disease. 
Front Neuroendocrinology, 30(2): 239-258.

[12] Bean, L. A., Lanov, L., Foster, T. C. M. (2014). Estrogen Receptors, the Hippocampus, and Memory. Neuroscientist, 20(5): 534-545.

[13] Eberling, J. L., Wu, C., Haan, M. N., Mungas, D., Buonocore, M., Jagust, W. J. (2003). Preliminary evidence that estrogen protects against age-related hippocampal atrophy. Neurobiol Aging, 24(5): 725-32.

[14] Epperson, C. N., Sammel, M. D., Freeman, E. W. (2013). Menopause Effects on Verbal Memory: Findings From a Longitudinal Community Cohort. J Clinical Endocrinol Metab., 98(9): 3829-3838.

[15] Braak, H., Braak, E. (1990). Alzheimer’s disease: striatal amyloid deposits and neurofibrillary changes. J Neuropathol Exp Neurol., 49: 215-224.

[16] Goodman, Y., Bruce, A. J., Cheng, B., Mattson, M. B. (1996). Estrogens Attenuate and Corticosterone Exacerbates Excitotoxicity, Oxidative Injury, and Amyloid $\beta$-Peptide Toxicity in Hippocampal Neurons. J of Neurochemistry, 66: 1836-1844.

[17] Gouldm E, Woolley, S. W., Frankfurt, M., McEwen, B. S. (1990). Gonadal Steroids Regulate Dendritic Spine Density in Hippocampal Pyramidal Cells in Adulthood. J of Neuroscience, 10(4): 1286-91.

[18] Packard, M. G., Teather, L. A. (1997). Intra-hippocampal estradiol infusion enhances memory in ovariectomized rats. Neuroreport, 29: 8(14): 3009-13.

[19] Barouk, S., Hintz, T., Ping, L., MacLusky, N. J., Scharfman, H. E. (2011). 17ß-Estradiol Increases Astrocytic Vascular Endothelial Growth Factor (VEGF) in Adult Female Rat Hippocampus. Endocrinology, 152(5): 1745-1751.

[20] Frankish, H., Horton, R. (2017). Prevention and management of dementia: a priority for public health. The Lancet, July 20, 2017. http://www.thelancet.com/journals/lancet/article/PIIS0140-6736(17)31756-7/fulltext.

[21] Shao, H., Breitner, J. C. S., Whitmer, R. A.,Wang, J., Hayden, K., Wengreen, H., et al. (2012). For the Cache County Investigators. Hormone therapy and Alzheimer disease dementia. New findings from the Cache County Study. Neurology, 79(18): 1846-1852.

[22] Kawas, S., Resnick, A., Morrison, R., Brookmeyer, M., Corrada, A., Zonderman, C., et al. (1997). A prospective study of estrogen replacement therapy and the risk of developing Alzheimer's disease. The Baltimore Longitudinal Study of Aging, https://doi.org/10.1212/WNL.48.6.1517.

[23] Whitmer, R. A., Quesenberry, Jr C. P., Zhou, J., Yaffe, K. (2011). Timing of hormone therapy and dementia: the critical window theory revisited. Annals Neurology, 69(1): 163-169.

[24] Craig, C. M., Maki, P. M., Murphy, D. G. M. (2005). The Women’s Health Initiative Memory Study: findings and implications for treatment. Lancet Neurol., 4: 190-194.

[25] Wang, P. N., Liao, S. Q., Liu, R. S., Liu, C. Y., Chao, H. T., Lu, S. R., et al. (2000). Effects of estrogen on cognition, mood, and cerebral blood flow in AD: a controlled study. Neurology, 54(11): 2061-6.

[26] Mulnard, R. A., Cotman, C. W., Kawas, C., van Dyck, C. H., Sano, M., Doody, R., et al. (2000). Estrogen replacement therapy for treatment of mild to moderate Alzheimer disease: a randomized controlled trial. Alzheimer's Disease Cooperative Study. JAMA, 283(8): 1007-15.

[27] Henderson, V. W., Paganini-Hill, A., Miller, B. L., Elble, P. F., Reyes, D., Shoupe, C. A., et al. (2000). Estrogen for Alzheimer's disease in women: randomized, double-blind, placebo-controlled trial. Neurology, 54(2): 295-301.

[28] Pintzka, C. W. S. and Håberg, A. K. (015). Perimenopausal hormone therapy is associated with regional sparing of the CA1 subfield: a HUNT MRI study. Neurobiology of Aging, 36: 2555-2562.

[29] Hill, A. B. (1965). The environment and disease: association or causation? Proc Royal Soc Med., 58: 295-300.

[30] Maki, P. M. (2013). The Critical Window Hypothesis of Hormone Therapy and Cognition: A Scientific Update on Clinical Studies. Menopause, 20(6): 695-709.

[31] Henderson, V. W., Benke, K. S., Green, R. C., Cupples, L. A., Farrer, L. A. (2005). Postmenopausal hormone therapy and Alzheimer's disease risk: interaction with age. J Neurol Neurosurg Psychiatry, 76(1): 103-5.

[32] Lord, C., Buss, C., Lupien, S. J., Pruessner, J. C. (2008). Hippocampal volumes are larger in postmenopausal women using estrogen therapy compared to past users, never users and men: A possible window of opportunity effect. Neurobiology of Aging, 29(1): 95-101.

[33] Majumdar, S. R., Almasi, E. A., Stafford, R. S. (2004). Promotion and prescribing of hormone therapy after report of harm by the Women's Health Initiative. JAMA, 292(16): 1983-1988.

[34] Anderson, G. L., Chlebowski, R. T., Aragaki, A. K., Kuller, L. H., Manson, J. E., Margery, G., et al. (2012). Conjugated equine oestrogen and breast cancer incidence and mortality in postmenopausal women with hysterectomy: extended follow-up of the Women's Health Initiative randomised placebo-controlled trial. The Lancet, 13: 476-86.

[35] Zhang, S. M., Manson, J. E., Rexrode, K. M., Cook, N. R., Buring, J. E., Lee, I. M. (2007). Use of oral conjugated estrogen alone and risk of breast cancer. Am J Epidemiol., 165(5): 524-9.

[36] Tabori, N. E., Stewart, L. S., Znamensky, V., Romeo, R. D., Alves, R. E., McEwen, B. S., et al. (2005). Ultrastructural evi- 
dence that androgen receptors are located at extranuclear sites in the rat hippocampal formation. Neuroscience, 130: 151-163.

[37] Pike, C. J. (2001). Testosterone attenuates b-amyloid toxicity in cultured hippocampal neurons. Brain Research, 919: $160-165$.

[38] Lv, W., Du, N., Liu, Y., Fan, X., Wang, Y., Jia, X., et al. (2016). Low Testosterone Level and Risk of Alzheimer's Disease in the Elderly Men: A Systematic Review and Meta-Analysis. Mol Neurobiol., 53(4): 2679-84.

[39] Public Health England. (2018). Prevention must be the heart of the NHS long-term plan. September 6. https://www.gov.uk/government/news/prevention-must-be-the-heart-of-the-nhs-long-term-plan. 